\title{
EDITORIAL
}

\section{Some long-standing issues in Portuguese phonology revisited in the laboratory}

\author{
Eleonora Albano ${ }^{1}$ and Didier Demolin ${ }^{2}$ \\ ${ }^{1}$ Department of Linguistics, University of Campinas, Campinas, SP, BR \\ ${ }^{2}$ Laboratoire de Phonétique et Phonologie, Sorbonne Nouvelle, Paris, FR \\ Corresponding author: Eleonora Albano (albano@unicamp.br)
}

This editorial to the Special Collection Laboratory Approaches to Portuguese Phonology aims at contextualizing the articles against the background of a two-century old scholarly tradition in the study of the Portuguese sound pattern. As foreseen in the Call for Papers, all the submissions received used laboratory methods to address long-standing issues raised by this tradition. Regardless of their publication order, the articles can be grouped into four topics: vowel variability, stress/stress-grouping, nasality, and fricative variability. Brief highlights on the works that paved the way for the state-of-the art in such topics are followed by comments on the gains introduced by the laboratory approach. Hopefully, this overview will help authors and readers evaluate the opportunities for further research along the lines indicated by the current results.

Keywords: laboratory phonology; Portuguese; vowel variability; stress/stress-grouping; nasality; fricative variability

In 2018, soon after the $16^{\text {th }}$ Conference on Laboratory Phonology, held in Lisbon in June 19-22, head organizer Sonia Frota, who is also the editor-in-chief of the Journal of Portuguese Linguistics, invited us to assemble a related Special Collection, initially conceived as a possible outlet for the papers on Portuguese presented in the conference. As pioneers of laboratory phonology in Brazil, we gladly accepted the challenge, and shortly submitted a call aimed at sparking the interest of the emerging community of laboratory phonologists working on Portuguese.

The call, launched in October 2018, invited two-page abstracts on any aspect of Portuguese phonology amenable to laboratory study. After a few deadline extensions, it closed in mid-February 2019. Thus, by early April, the authors of the selected proposals had been notified that the submission of their full papers was expected by August 15.

By then, little did we know that completion of the project would take about two years. This was because, in early 2020, Covid 19 heavily struck the lives of authors, editors, and reviewers alike. Delays became inevitable to accommodate unforeseeable constraints and setbacks. This scenario added an important nuance to the editors' job: it was necessary not only to advise the authors about revision points but also to encourage them to proceed in the face of adversity.

Fortunately, we managed to congregate a remarkably sensitive and competent team of reviewers. Without their support, the difficulties faced by this project might have been unsurmountable. They all readily understood that the majority of the participants was inexperienced in international publication. They all gladly expressed solidarity to our aim of providing a forum for this emerging community of debuting labphoners. We, therefore, cannot miss naming them. This is meant not only as an expression of gratitude but also as 
a way of disclosing their company to one another in this endeavor, which may eventually facilitate communication about shared interests.

In alphabetical order, we are pleased to acknowledge our debt to Alain Ghio, Beatriz Raposo de Medeiros, Brett Baker, Christopher Carignan, Clàudia Pons, Guilherme Duarte Garcia, Gunnar Hansson, Joan Birulés, Joaquin Romero, José Ignacio Hualde. Leendert Plug, Livia Oushiro, Luciana Pagan-Neves, Márcia do Carmo, Marcus Maia, Maria-Rosa Lloret, Natalia Guzzo, Olivier Crouzet, Pablo Arantes, Philipp Kramer, Rogeria Pereira, Ryan Shosted, Sarah Dugan, and Solange Rossato.

Another indispensable acknowledgement goes to Marisa Cruz, the Assistant Editor of JPL. Initially, she was unable to assist us, in order to avoid conflict of interest with the review of her own submission. However, since May 2020, when her article had just been published, she has been indefatigable in answering our queries about the journal site and in contributing to mitigate the authors' discomfort with the disrupting circumstances brought about by the pandemic.

We are also pleased to report that all the topics addressed by the submissions had concerned students of Portuguese for about two centuries. As might be recalled, the call predicted that long standing issues such as vowel variability, nasality, stress/stress grouping, and fricative variability might return under new guises, reshaped by the laboratory. And, indeed, they did - making it timely for us to pay respect to the acute intuitions of the pioneering men and women - grammarians, philologists, linguists, and phoneticians - who cleared the ground for contemporary work on Portuguese phonology.

Let us now turn to how the works presented here relate to this scholarly heritage. To this end, rather than a detailed review of the historical literature, we will offer a brief selection of notable works addressing problems similar to those treated by our contributors.

\section{Vowel Variability}

The low central vowel has been reported to display extensive dialectal variation in European Portuguese (henceforth EP) for centuries. For example, in his philosophical grammar, Barbosa (1871: 3) distinguishes between "á grande" - i.e., big á, the open variant - and "á pequeno", small a, the close variant. In a more detailed analysis, Viana (1973 [1892]: 13) presents a general vowel pyramid containing 44 vowels, of which 26 are attributed to the stressed variants of the vowels in different Portuguese dialects. Focusing on the $20^{\text {th }}$ century, Barbosa (1965) describes the pronunciation of stressed /a/ in Lisbon as much closer than its counterpart in the northern variety spoken in Braga.

A contemporary follow-up on this observation is presented here by Horn et al., who provide empirical evidence for dialectal variation in the perception of the central vowel $[\mathrm{a}, \mathrm{e}]$ in changing European Portuguese. The outcome of this study is that speakers of the northern dialect, spoken in the Braga region, display a general tendency to be inconsistent in the perception of the difference between the two stressed variants of the central vowel. The results imply that the gradual loss of the production distinction between [a] and [ $\mathrm{e}$ ] is reflected in perception, and that this effect is influenced by the stress pattern, as in many other cases.

Another long-standing issue in Portuguese phonology is vowel-to-vowel interactions across syllables. In his guide to Portuguese pronunciation, Viana (1973: 57-58) uses the term 'metaphony' to designate the influence of an unstressed vowel on a preceding stressed vowel. Later, Mateus (1975) resorts to the term 'vowel harmony' to describe the morphologized influence of a truncated theme vowel on mid stem vowels of the second and third verb conjugations, as in 'sinto', I feel, vs. 'sente', s/he, it feels.

This kind of verb alternation is in fact likely to have originated in a vowel harmony process active in the language in the Middle Ages, while theme vowels weakened and fell. 
In a study of manuscripts from the $13^{\text {th }}$ through the $16^{\text {th }}$ centuries, Fonte (2017) amassed a sizeable number of examples of a germane process, whereby mid prestressed vowels are raised in the presence of a following high stressed vowel.

As to Brazilian Portuguese (henceforth BP), an influential work by Camara Jr. (2019[1970]: 70-71) noted the productivity of raising harmony in the colloquial speech in Rio de Janeiro, in words such as ' $m[i]$ nino', lad, or ' $f[u] l i n h a$ ', calendar. This inspired a number of variationist studies - starting with Bisol (1981), to document height harmony in several dialects in both the raising and the lowering directions.

Madruga, Hamann and Abaurre look into the connection between vowel harmony, stress, and gradient assimilation by focusing on lowering. The use of the [Low] feature is proposed to account for an acoustic analysis showing a higher $\mathrm{F}_{1}$ for [e, o] before stressed low-mid vowels. This new proposition raises new questions about the phonetic actuation of harmony processes that are still too often reduced to an ad hoc use the [ATR] feature. It also opens a path for future research to consider the entire F-pattern $\left(\mathrm{F}_{1} / \mathrm{F}_{2} / \mathrm{F}_{3} / \mathrm{F}_{4}\right)$ of lowered vowels, looking into measurements of the higher formants in search for further explanations of harmony.

\section{Stress and prosodic grouping}

Early grammarians and phoneticians specified large vowel inventories with fine timber distinctions attributable to stress position. For example, Barbosa (1871: 4) asserted that Portuguese had twenty vowels, listing a number of open and close variants of the low and mid vowels. Viana (1973: 55) was even more explicit about unstressed vowel reduction. He put together a "correspondence table" between stressed and unstressed vowel variants, taking into consideration not only position (initial, medial, and final), but also adjacency (before or after vowel or consonant, with special attention to palatals). Vowel quality is thus traditionally considered a cue to stress position in addition to duration and intensity.

Harmath-de-Lemos discusses aspects of primary stress detection in continuous speech in Brazilian Portuguese. Her results indicate that stress, as processed by mel frequency spectral coefficients (MFCCs) and hidden markov models-gaussian merging (HMM-GMs), relies on various acoustic properties of the speech signal directly computable from the spectrum, and not affected by duration or $\mathrm{F}_{0}$. This marks a departure from previous literature and opens a path for a different kind of analysis of primary stress in Brazilian Portuguese. A key point is that the study of primary stress may benefit from a good match between linguistic and engineering methods.

Another salient property of stress is to group words. In BP, the seminal work on this topic is Camara Jr.'s description of the phonological as opposed to the morphological word (2019: 93-98). Later, his elegant, minimal stress grouping was the point of departure for a number of more detailed descriptions based on Nespor and Vogel's Prosodic Phonology (1986).

Silva and Tenani analyze syllable duration and $\mathrm{F}_{0}$ variation as cues for distinguishing the prosodic status of prepositional clitic-host sequences from prosodic word sequences in Brazilian Portuguese. More specifically, they investigate the phonetic realization of unstressed syllables at prosodic word boundaries. An important point concerns the failure of duration to distinguish the prosodic word from the clitic prosodization sequences. Another is whether the pitch range can be a cue for such a distinction. Results show that $\mathrm{F}_{0}$ variations support the interpretation that prosodic word sequences are different from clitic-host sequences. Therefore, could the $\mathrm{F}_{0}$ variation signal an intonation associated to the clitic-host sequences distinct from prosodic word sequences? The authors leave the discussion open, encouraging the addition of more empirical data to the debate on the 
prosodic status of clitics in Brazilian Portuguese. A promising direction for future research is to focus on micro-prosodic variations of $\mathrm{F}_{0}$ in clitic-host sequences.

Finally, as seen above, the multiplicity of cues to the Portuguese stress contour has long called attention. This problem naturally calls for laboratory elucidation. An early attempt is due to Martins (1988: 155-157), who devised some auditory tests to compare listeners' reactions to the three stress patterns of EP (antepenultimate, penultimate and final). Her main finding was that that they were not equally recognizable: penultimate stress, the most frequent, was the easiest, followed by final and antepenultimate. Surprisingly, this is not the case in language acquisition, at least in the visual domain.

Cruz, Butler, Severino, Filipe and Frota examine eye gaze in a stress perception experiment with European Portuguese learning infants. Results show that the eye gaze exploration of talking faces by 5-6 month old EP-learning infants adds to previous findings of attention to visual speech cues at this age. This suggests that increased support from visual signals in early language acquisition contributes to sediment the relation between the auditory and visual aspects of language. A particular point from this study that invites further exploration is the reason for the infants' preference of iambic as opposed to trochaic stress, previously shown to be auditorily favored by adults. Is this specific to the acquisition of European Portuguese? Or does it reflect some intrinsic physiological aspect of visual learning?

\section{Nasality}

Long before becoming an object of phonetic concern, the problem of the Portuguese nasal coda was reflected in the instability of spelling. Spelling reforms have always disputed the use of ' $m$ ', ' $n$ ' and tilde. Barbosa (1871: 13) noted such fluctuations and reflected on their Romance origins:

Este $n$ em logar de til, teria o seu logar proprio immediatamente depois da prepositiva, se em vez de escrever mains, maons, sermoens, beens, ruins, escrevêssemos manis, manos, sermones, benes, runis. Mas esta escriptura tinha o inconveniente de fazer do $n$ signal de nasalidade, em $n$ consoante pela vogai que se lhe segue, como fazem os hespanhoes. Para evitar pois este absurdo, caiu no outro de pôr o signal nasal fóra do seu logar.

This ' $n$ ' instead of tilde would have its own place immediately after the prepositive, if instead of writing 'mains, maons, sermoens, bens, ruins', we wrote 'manis, manos, sermons, benes, runis'. But this spelling had the inconvenience of turning ' $n$ ' into a nasal sign, like the consonantal ' $n$ ' for the following vowel, as done by the Spanish. To avoid such absurdity, it fell into another: putting the nasal sign outside its proper place.

[translated by the authors]

The most famous attempt to deal with the fleeting nature of coda nasality is Camara Jr.'s archiphoneme analysis (1977[1953]; 2019). As this hypothesis is still amply debated, it is not surprising that this $S C$ offers two laboratorial alternatives to it, one based on perception data and the other based on production data.

Marques and Scarborough's treatment of the acoustics of nasality uncovers differences in the implementation of nasalized as opposed to nasal vowels that directly bear on perception. The finding that the rapid implementation of the acoustics of nasality in nasal vowels blocks perceptual compensation has several important consequences as regards the timing, profile, and degree of nasality. It suggests that velum port opening is a dynamic 
process and not a simple binary feature, a point which is not sufficiently explored in treatments of nasal processes in Brazilian Portuguese. The article thus opens new perspectives for future research on the dynamics of nasality, taking Brazilian Portuguese as a reference point.

Rothe-Neves offers a well-documented study of durational aspects of vowel nasalization based on nasal airflow measurements of Brazilian Portuguese. Aerodynamic studies are still too rare, and this is a precious addition to this type of experimental data. Two points deserve emphasis. The first is the observation that regressive nasalization is part of the BP system and not just an automatic process. The second is that nasalization remains constant in duration while the vowel accommodates to the following consonant. Both points clearly suggest that nasalization is a dynamic process. They thus converge with Marques and Scarborough's observations and reinforce the need for further studies on the dynamics of velum port opening in both the aerodynamic and the articulatory dimensions.

\section{Fricative variability}

Finally, the variability of fricatives, especially coda sibilants, is also of traditional concern to students of Portuguese. For example, Viana (1973: 24-25) asserts that certain consonants can constitute a syllable on their own. These are the sibilants, the liquids, and the nasals. However, his examples of the latter two classes involve interjections only, whereas, in the case of sibilants, the instability of the initial vowel in words beginning with 'es' is explicitly noted. Thus, his transcription of the first stanza of Camões's "Lusíadas" (1973: 100) displays a mute [e] before the [s] of "esforçados", hardworking, masc. plural.

Cristófaro-Silva and Freitas's treatment of vowel-zero alternation in word-initial sC-clusters addresses important and yet unresolved issues on the relation between phonetics and phonology. In loan and native word-initial (e)sC-clusters, vowel duration triggers differences in the length of the sibilant whenever an underlying or prothetic vowel is present. This may reflect dynamic overlap processes that are not yet fully understood. A crucial point emerging from such results is that sub-phonemic properties captured by experimental observations, and, thus, phonetic in nature, characterize phonetic details relevant for the shaping of lexical representations. The fact that some of these details are not in a one-to-one correspondence with phonological categories or representations forces phonology to integrate several new dimensions. Such unresolved issues, however complex, hold a promise for future research.

Another historical process fit for laboratory study is intervocalic sibilant voicing, present in the language since the time of Galician Portuguese, i.e., between the $12^{\text {th }}$ and the $14^{\text {th }}$ centuries.

Alves and Brisolara discuss the role of fricative voicing and length of the preceding vowel in the identification of minimal pairs involving voiced and voiceless alveolar fricatives as produced by Spanish $\mathrm{L}_{1}$ speakers. The research aims at relating $\mathrm{L}_{2}$ teaching to a theoretical discussion of dynamical aspects of speech production. As expected, the results provide suggestions for increasing the intelligibility of accented speech in $\mathrm{L}_{2}$ classes of Brazilian Portuguese. Another aim of the study is to support a gestural account of speech based on the role of acoustic-articulatory cues in speech perception, as proposed by Albano (2001). An important implication is that the investigation of perceptual cues in listeners with different backgrounds may improve $\mathrm{L}_{2}$ teaching and, at the same time, further the understanding of speech dynamics.

Another path opened by the laboratory study of sibilants is to widen the understanding of different shades of the identities associated with the hissing and hushing variants in coda position. 
Biasibetti's study of allophonic variation of the archiphoneme /S/ in coda position raises issues of the cognitive biases in the sociophonetics in Brazilian Portuguese. The results are, in a way, a good illustration of Labov's (1981) discussion of changes that are above or below the level of consciousness. They show that changes above the level of consciousness play a role in the social perception of coda /S/ in the different Florianopolitan varieties. By integrating the cognitive and sociophonetic dimensions explicitly, such observations encourage researchers to approach the same questions under more controlled laboratory conditions.

Finally, laboratory studies of children's speech can throw light on segment instability. This was the concern of Berti et al., who investigated whether perception and production errors are correlated in the speech of children diagnosed with Speech Sound Disorder.

Berti, Guilherme, Esperandino and Oliveira explore aspects of children speech sound disorders. Although they find one case of positive correlation between speech perception and production, the overall implication of the study is that speech perception does not necessarily mirror speech production. Among the consonantal categories analyzed, perceptual accuracy is much less obvious for fricatives. The authors observe that recurrent otitis media and ensuing fluctuations in hearing sensitivity during the preschool years might interfere with learning to identify the acoustic cues that are critical for perceiving fricative contrasts. This mirrors findings on Australian native languages made by Butcher et al. (2012), who suggest that chronical otitis in these communities likely impeded the implementation of fricatives in their sound systems, as otitis triggers a loss of auditory sensitivity in frequencies above $5000 \mathrm{~Hz}$, which are necessary to perceive sibilant fricatives.

\section{Final remarks}

This SC has assembled two articles on EP and nine on BP. However, caution should be taken against interpreting these numbers as indices of the amount of laboratory work done on either side of the Atlantic. They probably just indicate the eagerness of the Brazilian scientific community for international visibility, given its geographical isolation. We are thus pleased that this $S C$ has succeeded in opening a forum whereby spatially distant peers can take cognizance of one another's work and start sharing research questions and interests.

Another characteristic of this $S C$ is that most results constitute preliminary inferences based on minimal equipment, a small number of participants, and basic statistical analysis performed on basic measurements. This entire $S C$ can thus be regarded as a clearing of the ground for further laboratory research on the same topics. May it encourage the authors and readers to persist in pursuing the same long-standing issues from a closer and deeper laboratory perspective.

\section{Competing Interests}

The authors have no competing interests to declare.

\section{References}

Albano, E. C. (2001). O gesto e suas bordas: Esboço de fonologia acústico-articulatória do português brasileiro [Gestures and their edges: An outline of an acoustic-articulatory phonology of Brazilian Portuguese]. Campinas: Mercado de Letras/São Paulo Fapesp.

Alves, U. K., \& Brisolara, L. B. (2020). Listening to accented speech in Brazilian Portuguese: On the role of fricative voicing and vowel duration in the identification of /s/ - /z/ minimal pairs produced by speakers of L1 Spanish. Journal of Portuguese Linguistics, 19(1), 6. DOI: https://doi.org/10.5334/jpl.237 
Barbosa, J. M. (1965). Etudes de phonologie portugaise [Studies in Portuguese phonology]. Lisboa: Junta de Investigações Científicas do Ultramar.

Barbosa, J. S. (1871). Grammatica philosophica da lingua portugueza [A Philosophical Grammar of the Portuguese Language] ( $5^{\text {th }}$ edition). Lisboa: Tipografia da Academia Real de Ciências. Digital copy of a printed $5^{\text {th }}$ edition original, retrieved from https:// bibdig.biblioteca.unesp.br/handle/10/6903 on March 24, 2021.

Berti, L. C., Guilherme, J., Esperandino, C., \& de Oliveira, A. M. (2020). Relationship between speech production and perception in children with Speech Sound Disorders. Journal of Portuguese Linguistics, 19(1), 13. DOI: https://doi.org/10.5334/ jpl.244

Biasibetti, A. P. C. da S. (2020). Cognitive biases on the social perception of the allophonic variation of coda /S/ in Brazilian Portuguese. Journal of Portuguese Linguistics, 19(1), 9. DOI: https://doi.org/10.5334/jpl.233

Bisol, L. (1981). Harmonização vocálica: Uma regra variável [Vowel Harmony: A variable rule]. (Unpublished doctoral dissertation). Universidade Federal do Rio de Janeiro.

Butcher, A., Stoakes, H., Fletcher, J., \& Tabain, M. (2012). Speaking and hearing Australian Aboriginal languages: Could hearing impairment play a role in the evolution of a phonology? 2nd Workshop on Sound Change, Kloster Seeon.

Camara, J. M., Jr. (1977[1953]). Para o estudo da fonêmica portuguesa [For the study of Portuguese phonemics]. Rio de Janeiro: Padrão.

Camara, J. M., Jr. (2019[1970]). Estrutura da língua portuguesa [The structure of the Portuguese language]. Critical edition with notes by E. G. Pagotto, M. C. F. Silva, \& M. M. S. Almeida. Petrópolis: Vozes.

Cristófaro-Silva, T., \& Freitas, M. (2020). sC-clusters in Brazilian Portuguese. Journal of Portuguese Linguistics, 19(1), 14. DOI: https://doi.org/10.5334/jpl.231

Cruz, M., Butler, J., Severino, C., Filipe, M., \& Frota, S. (2020). Eyes or mouth? Exploring eye gaze patterns and their relation with early stress perception in European Portuguese. Journal of Portuguese Linguistics, 19(1), 4. DOI: https://doi.org/10.5334/ jpl.240

Fonte, J. M. (2017). The unstressed vocalism in the history of portuguese. Alfa, Revista de Linguística, 61(1), 165-196. DOI: https://doi.org/10.1590/1981-5794-1704-7

Harmath-de-Lemos, S. (2021). Detecting word-level stress in continuous speech: A case study of Brazilian Portuguese. Journal of Portuguese Linguistics, 20(1), 3. DOI: https:// doi.org/10.5334/jpl.238

Horn, V., Rinke, E., \& Flores, C. (2020). Dialectal Variation in European Portuguese Central Vowel Perception. Journal of Portuguese Linguistics, 19(1), 1. DOI: https://doi. org/10.5334/jpl.232

Labov, W. (1981). Resolving the neogrammarian controversy. Language, 57(2), 267-308. DOI: https://doi.org/10.2307/413692

Madruga, M. R., Hamann, S., \& Abaurre, M. B. M. (2020). Gradient and categorical assimilation of pretonic vowels in Brazilian Portuguese. Journal of Portuguese Linguistics, 19(1), 12. DOI: https://doi.org/10.5334/jpl.234

Marques, L., \& Scarborough, R. (2020). Perceptual Compensation of Vowel Nasality in Brazilian Portuguese. Journal of Portuguese Linguistics, 19(1), 3. DOI: https://doi. org/10.5334/jpl.230

Martins, M. R. D. (1988). Ouvir falar: Introdução à fonética do português [Hearing and talking: An introduction to the phonetics of Portuguese]. Lisboa: Editorial Caminho.

Mateus, M. H. M. (1975). Aspectos da fonologia portuguesa [Aspects of Portuguese phonology]. Lisboa: Instituto Nacional de Investigação Científica. 
Nespor, M., \& Vogel, I. (1986). Prosodic phonology. Dordrecht: Foris Publications.

Rothe-Neves, R. (2021). Durational aspects of tautosyllabic vowel nasalization in (Brazilian) Portuguese: An airflow investigation. Journal of Portuguese Linguistics, 20(1), 5. DOI: https://doi.org/10.5334/jpl.236

Silva, L., \& Tenani, L. E. (2021). Prosodization of prepositional clitics and prosodic words in Brazilian Portuguese: Investigation of phonetic cues. Journal of Portuguese Linguistics, 20(1), 7. DOI: https://doi.org/10.5334/jpl.235

Viana, A. R. G. (1973 [1892]). Estudos de fonética portuguesa [Studies in Portuguese phonetics]. Lisboa: Imprensa Nacional-Casa da Moeda.

How to cite this article: Albano, E., \& Demolin, D. (2021). Some long-standing issues in Portuguese phonology revisited in the laboratory. Journal of Portuguese Linguistics, 20: 6, pp. 1-8. DOI: https://doi.org/10.5334/jpl.275

Copyright: $\odot 2021$ The Author(s). This is an open-access article distributed under the terms of the Creative Commons Attribution 4.0 International License (CC-BY 4.0), which permits unrestricted use, distribution, and reproduction in any medium, provided the original author and source are credited. See http://creativecommons.org/licenses/ by $/ 4.0 /$.

] $\mathrm{u}[\quad$ Journal of Portuguese Linguistics is a peer-reviewed open access journal published by Ubiquity Press. 